\title{
Avaliação da composição de espécies de macrófitas aquáticas em ecossistemas lênticos perenes do Parque das Dunas, Salvador (BA)
}

Esthalin M. da Silva de Souza Laís C. de Santana Moreira
Universidade Católica do Salvador. UCSal.

E-mails: esthalin.moreira@gmail.com laiscardosobbio@hotmail.com

Recebido: 15 mar. 2017. Revisado: 21 mar. 2017 Aceito: 02 abr. 2017.

DOI: http://dx.doi.org/10.21674/2448-0479.34.807-820

\section{Resumo}

Os ecossistemas aquáticos continentais representam um sistema ainda pouco conhecido e bastante ameaçado pela ação do homem, principalmente as regiões litorâneas que sofrem com a especulação imobiliária, turística e industrial. As macrófitas aquáticas são essenciais ao equilíbrio do ambiente aquático, pois sustentam um grande número de organismos e respondem bem a diferentes gradientes ambientais que são formados lateralmente e ao longo do manancial. Tendo em vista que a depleção da qualidade da água dos recursos hídricos, principalmente em ecossistemas lênticos do litoral norte do estado da Bahia, está aumentando drasticamente devido às ações antrópicas. O presente trabalho busca avaliar a composição de espécies de macrófitas aquáticas em ecossistemas lênticos do Parque das Dunas, o último manancial urbano do ecossistema de dunas, lagoas e restingas do Brasil. O levantamento florístico e coleta de amostras de água foram realizados em todas as lagoas perenes do parque entre os meses de novembro e dezembro de 2015. Foram realizadas cinco visitas ao parque, com 8 horas diárias, totalizando 40 horas de atividades de campo. No inventário florístico foram registradas 40 espécies, distribuídas em 35 gêneros e 24 famílias, bem como a análise de parâmetros físico-químicos. Esses resultados são dados 
importantíssimos que ajudarão subsidiar ações de planejamento ambiental e manejo das macrófitas aquáticas do parque, e em regiões alagadas do ecossistema de restinga.

Palavras-chave: Parâmetros físico-químicos. Lagoas. Restinga.

\section{Introdução}

Os ecossistemas aquáticos possuem grande importância dentre os ecossistemas brasileiros e estudos a cerca desses ambientes têm evidenciado uma elevada biodiversidade de organismos, destacando desta forma, seu alto valor social e econômico (Cervi et al., 2009). Segundo Esteves (1998), Bove et al. (2003) e Junk et al.(2014), as áreas alagadas compreendem aproximadamente $20 \%$ da superfície do território brasileiro, possuem uma importante biodiversidade, especialmente os de água doce, e representam um sistema ainda pouco conhecido e bastante ameaçado pela ação do homem.

Historicamente, as áreas úmidas têm recebido pouca atenção da sociedade e um percentual considerável delas tem sofrido alterações significativas para diversos fins, principalmente as regiões litorâneas. Essas transformações estão diretamente relacionadas aos impactos antrópicos, como aproveitamento agrícola, industrial e imobiliário que além de alterar as características físicas e químicas da água, influenciam também a estrutura das diversas comunidades locais (Mauhs et al., 2006; Tinôco et al., 2008).

A Bahia possui o mais extenso litoral do Brasil, com aproximadamente $1.150 \mathrm{~km}$, sendo que, a costa litorânea do norte da Bahia abrange $220 \mathrm{~km}$ onde estão inseridas sete Unidades de Conservação, sendo a maioria destas, Áreas de Proteção AmbientalAPA, as quais cobrem uma extensão de aproximadamente 215 mil hectares (Menezes et al., 2009). O litoral norte da Bahia apresenta uma estreita faixa de planície quaternária com até $10 \mathrm{~km}$ de largura, com fitofisionomia marcante e características edafoclimáticas singulares, como extensas áreas úmidas (Menezes, 2007; INEMA, 2015). Esta vasta distribuição de áreas úmidas, tais como: estuários, manguezais, 
brejos, lagoas, lagunas e rios que são ecossistemas na interface entre ambientes terrestres e aquáticos, doces, salobras ou salgadas, naturais ou artificiais, continentais ou costeiros, permanentemente ou periodicamente inundados por águas rasas ou com solos encharcados, com comunidades de animais e plantas adaptadas à sua dinâmica hídrica (Junk et al., 2014; Pott et al., 2012; Azevedo et al., 2014).

A capital do estado da Bahia, Salvador, tem grande abundância de águas superficiais e subterrâneas, parte das águas superficiais encontra-se distribuída nas diversas lagoas e rios espalhados pela cidade (Santos et al., 2010). Na porção extrema nordeste de Salvador, representando o ponto de interseção com o Litoral Norte da Bahia, vetor de expansão urgana da região metropolitanda, está localizada a area de Proteção Ambiental (APA) Lagoas e Dunas do Abaeté (Decreto Estadual $n^{\circ} 351$ de 22 de setembro de 1987), e nela está inserido o Parque das Dunas, que possui dezenas de lagoas sazonais e perenes de águas escuras e intercaladas por dunas de areia branca (INEMA, 2015).

As lagoas são ecossistemas lênticos, de origem natural ou antrópica, sendo consideradas importantes reservatórios de água, essenciais para a sobrevivência de muitas plantas e animais (CONAMA, 2005; Tundisi, 2006; Tundisi \& Matsumura-Tundisi, 2008). No que se refere à flora, os ecossistemas lênticos são ambientes com alta riqueza em espécies e constituem-se como áreas extremamente produtivas (Pollock et al., 1998; Cunha-Santino \& Bianchini Jr., 2011). A vegetação a eles associada compreende não apenas as hidrófitas propriamente ditas, como também as plantas que periodicamente estão submersas em diversos níveis ou as que margeiam estes ambientes, como por exemplo, as espécies anfíbias, desta maneira a existência de distintos grupos confere a esses organismos grande amplitude ecológica (Pott et al., 2000; Cervi et al., 2009).

Tendo por base que as macrófitas aquáticas respondem bem a diferentes gradientes ambientais, sendo indispensáveis ao equilíbrio do ambiente aquático, despertou-se o interesse em entender a composição de espécies de macrófitas aquáticas em ecossistemas lênticos perenes do Parque das Dunas. Inventariar a flora de macrófitas aquáticas. Analisar as características físico-químicas dos ecossistemas 
lênticos perenes. Investigar a relação da distribuição espacial das macrófitas com os parâmetros físico-químicos. Desta forma, esta pesquisa fornecerá subsídios para o manejo adequado das comunidades de macrófitas aquáticas, e para utilização racional das áreas hídricas e alagáveis, visto que, a região onde está localizado o parque é uma área extremamente requisitada, para empreendimentos imobiliários, industriais e turísticos (Tinôco et al. 2008; INEMA, 2015).

De acordo com Esteves (1998; 2011) e CONAMA (2005), os ecossistemas lênticos são locais de águas quase paradas ou lentamente renovadas sem comunicação direta com o mar e suas águas têm em geral baixo teor de íons dissolvidos, quando comparadas às águas oceânicas e não são elementos permanentes da paisagem da terra, pois eles são fenômenos de curta durabilidade na escala geológica. Em geral, apresentam padrões verticais e horizontais das variáveis físicas, químicas e biológicas que influenciam diretamente a composição, a estrutura e a dinâmica da comunidade biótica e são classificados em região litorânea ou ripária, região limnética ou pelágica, região bentônica e interface água-ar (Cunha-Santino \& Bianchini Jr., 2011).

A definição do termo macrófita aquática não é consensual, a terminologia tem gerado discussão em meio cientifico desde o início dos estudos desses organismos (Pompêo \& Moschini-Carlos, 2003; Esteves, 2011). O conceito mais habitual de macrófitas aquáticas foi proposto por Irgang \& Gastal Jr. em 1996, onde consideram os vegetais visíveis a olho nu, com partes fotossinteticamente ativas permanentemente, ou por diversos meses, total ou parcialmente submersas em água doce ou salobra, podendo ainda ser flutuantes.

Dada à heterogeneidade filogenética e taxonômica das macrófitas aquáticas, estes vegetais são preferencialmente classificados quanto ao seu biótopo. Esta classificação reflete o grau de adaptação das macrófitas ao meio aquático. Onde em um extremo estariam as macrófitas anfíbias que são ora emersas, ora submersas, enquanto no outro extremo encontram-se as submersas, limitadas inteiramente ao ambiente subaquático (Esteves, 1998; 2011). 


\section{Material e Métodos}

As atividades de campo foram iniciadas a partir da análise e reconhecimento da área de estudo, após a fotointerpretação inicial de uma ortofoto, projeção em UTM SAD 69/WGS84 e imagens do Google Earth Pro, desta forma, foi possível elencar as dez lagoas perenes existentes (Lagoa Dois Dois - A; Lagoa Dois Dois - B; Lagoa dos Líderes; Lagoa da Alameda; Lagoa do Aeroporto; Lagoa do Junco; Lagoa da Vitória; Lagoa da Baronesa; Lagoa do Camarão e Lagoa do Jacaré).

O levantamento florístico foi realizado em todas as lagoas perenes do Parque das Dunas entre os meses de novembro e dezembro de 2015. Foram realizadas 5 visitações ao parque, sendo que cada visita ocorreu uma vez por semana, perfazendo 5 semanas, com 8 horas diárias, totalizando 40 horas de atividades de campo. Durante o período de observação, foram verificadas duas lagoas por dia, sendo disponibilizado 4 horas pela manhã para uma lagoa e 4 horas pela tarde para lagoa seguinte. Em cada visita às lagoas, foi realizado o georreferenciamento e o inventário florístico com simultânea coleta das amostras de água para as análises laboratoriais dos parâmetros físico-químicos. O esforço amostral foi realizado tomando por referência os maiores bancos de macrófitas aquática, as margens foram circundadas adentrando a lagoa em direção ao centro até o limite da zona eufótica a fim de abranger todas às formas biológicas das macrófitas aquáticas na amostragem. Durante este período foi realizado o registro fotográfico e para a identificação das espécies foi utilizado o método de observação direta, consulta a especialistas e bibliografias especializadas (Lorenzi, 1992; Santos, 2010).

A revisão nomenclatural das espécies foi feita utilizando-se das informações do site Flora do Brasil, a classificação das famílias botânicas fanerogâmicas baseou-se em Souza \& Lorenzi (2008) e em APG III (2009).

Foram realizadas medidas in loco concomitantemente ao inventário florístico, a concentração de oxigênio dissolvido ( $\mathrm{mg} / \mathrm{l})$ e temperatura (oC) 
da água com medidor portátil de Oxigênio Dissolvido e Temperatura HI 9146 Hanna Instruments. As amostras das águas em estudo foram coletadas em pontos aleatórios das dez lagoas perenes, em recipientes de $500 \mathrm{ml}$ de polietileno, exaustivamente lavados e enxaguados previamente com água deionizada, em seguida foram realizadas lavagens com a água da lagoa a ser amostrada, a fim de evitar possíveis interferências. As amostras foram recolhidas a 30 centímetros da superfície, onde todo recipiente foi mergulhado na água, tendo a preocupação de não deixar ar nas garrafas. Em seguida, foram acondicionadas em recipiente térmico com gelo e transportadas para o laboratório de químico de águas e efluente da empresa GE Water \& Process Technologies, localizado no Polo Petroquímico de Camaçari-BA, onde foram realizadas às análises físicoquímicas. Os parâmetros mensurados em laboratório foram: $\mathrm{pH}$, amônia (ppm), condutividade elétrica ( $\mu \mathrm{S} . \mathrm{cm}-1), \mathrm{DQO}(\mathrm{ppm})$, fósforo total (ppm) e turbidez (NTU).

\section{Resultados e Discussão}

No levantamento florístico foram registradas 40 espécies, distribuídas em 35 gêneros e 24 famílias. As famílias mais representativas, em número de espécies, foram: Cyperaceae com sete espécies e Poaceae com cinco espécies.

A família Fabaceae obteve três espécies; Araceae, Lentibulariaceae, Melastomataceae, Salviniaceae com duas espécies cada e Asteraceae, Blechnaceae, Bonnetiaceae, Cabombaceae, Commelinaceae, Convolvulaceae, Dennstaedtiaceae, Juncaceae, Lycopodiaceae, Lythraceae, Malvaceae, Mayacaceae, Nymphaeaceae, Onagraceae, Piperaceae, Rubiaceae e Xyridaceae, todas com uma espécie cada.

Em relação às formas biológicas das macrófitas aquáticas encontradas no estudo, $87 \%$ das plantas encontradas se 
enquadraram nas categorias anfíbias e emergentes, sendo que, $69 \%$ foram anfíbias e $18 \%$ emergentes, $5 \%$ submersa fixa, $3 \%$ flutuantes livres, $3 \%$ flutuantes fixas, $2 \%$ submersas livres e não houve a presença de epífitas.

As 40 espécies encontradas no presente estudo, evidenciam a importante participação das macrófitas aquáticas na biodiversidade dos ambientes lênticos da área estudada. Esses resultados demonstram uma riqueza expressiva e semelhante a outros trabalhos desenvolvidos em ecossistemas lênticos. A exemplo, Mauhs et al., (2006) listaram 18 espécies e 11 famílias em uma área úmida na planície costeira do Rio Grande do Sul. Neves et al., (2006) registraram 28 espécies distribuídas em 20 famílias para uma lagoa de planície costeira no município de Candeias, Bahia. Paz \& Bove (2007) na Lagoa de Carapebus situada no Parque Nacional da Restinga de Jurubatiba registraram 42 espécies, subordinados a 38 gêneros distribuídos em 27 famílias.

No que se refere às formas biológicas, geralmente o número de espécies anfíbias e emergentes são maiores que o das demais formas biológicas nos trabalhos de macrófitas aquáticas (Rodrigues et al., 2015; Macedo et al., 2015). Isso ocorre porque as plantas anfíbias possuem adaptações tanto para o ambiente terrestre quanto para ambiente aquático (Irgang \& Gastal Jr., 1996), e as emergentes porque ficam localizadas nas zonas litorâneas, áreas de grande produtividade e diversidade de espécies, e também onde são encontradas as maiores concentrações de nutrientes (Wetzel, 2001; Esteves, 1998; 2011).

Assim como nas pesquisas de Fonseca \& Bicudo (2011); Rolon, (2011); Fermino et al., (2011), Macedo et al., (2015) e Rodrigues et al., (2015), esse ordenamento se manteve nas lagoas estudadas, onde as áreas colonizadas pelas macrófitas, na grande maioria das vezes, se restringiram a região litorânea, onde a 
predominância dos grupos de anfíbias e emergentes favoreceu a formação de bancos de macrófitas em diversas lagoas, processos de infestação na Lagoa do Junco e um estágio mais avançado na Lagoa do Jacaré. Essa distribuição pode ser explicada a partir dos resultados obtidos por Pott et al., (1989); Alves et al., (2011) e Lacet (2014), que através da análise da composição e distribuição de macrófitas aquáticas em lagoas, observaram que houve maior abundância de espécies na zona marginal da lagoa, onde os níveis de água são menores, a variação no nível de água é mais intensa que nas demais egiões e essas zonas constituem a interface entre o ambiente aquático e o terrestre, formando habitat heterogêneo.

Em pesquisas com macrófitas aquáticas, as famílias Cyperaceae e Poaceae, geralmente aparecem entre as três principais famílias em relação à riqueza e abundância (Paz \& Bove, 2007; Ferreira et al., 2010; Alves et al ., 2011; Araújo et al., 2012; Pinheiro \& Jardim, 2015). No presente estudo esta mesma tendência se manteve. Segundo Rutishauser, (2010) apud Rodrigues, (2011), a razão para esperar que as famílias Cyperaceae e Poaceae apresentem maiores riquezas de espécies, está em sua representatividade em estudos florísticos, sendo $30 \%$ e $\quad 9 \%$ respectivamente, além disso, por possuírem sistema subterrâneo complexo formado por rizomas e tubérculos, com algumas dispondo de estolhos subterrâneos, permitindo eficiente propagação vegetativa e, consequentemente, representando espécies competitivamente dominantes (Prata et al., 2007; Lopes et al., 2014; Araújo et al., 2015).

Em relação aos parâmetros físico-químicos estudados, eles sofrem influência direta da abundância das macrófitas aquáticas, bem como, influenciam a presença ou ausência das mesmas (Meyer \& Franceschinelli, 2011). Um dos parâmetros utilizados, a temperatura, é considerada um importante fator limitante de 
produtividade primária, respiração dos organismos e decomposição da material orgânica, sendo também um importante influenciador nas propriedades físico-químicas da água. A elevação da temperatura em um corpo d'água geralmente ocorre pela incidência de radiação solar e/ou despejos industriais, entretanto, o observado nas lagoas em estudo é que a temperatura está diretamente relacionada com a radiação solar, uma vez que, não foram observados aportes de efluentes.

Através dos resultados obtidos, foi possível verificar que não apresentaram oscilações relevantes entre as lagoas, onde a variação ocorrida da menor temperatura para maior foi de $4,8{ }^{\circ} \mathrm{C}$, onde as lagoas com temperaturas mais baixas (Lagoa da Baronesa com 28,6 ${ }^{\circ} \mathrm{C}$ e Lagoa dos Líderes com $29,7{ }^{\circ} \mathrm{C}$ ) estão localizadas em áreas com maior cobertura vegetal arbórea em torno das margens, cobrindo parcialmente ou totalmente a lâmina d'água. Desta forma, estão menos expostas a incidência dos raios solares. Já as lagoas com temperaturas mais elevadas (Lagoa do Aeroporto com 33,4 oC e Lagoa da Vitória $32,6{ }^{\circ} \mathrm{C}$ ) estão localizadas em regiões mais abertas, com pouca ou nenhuma cobertura vegetal em torno das margens, logo, mais expostas à radiação solar. Sendo que, a Lagoa do Aeroporto, se comparada às outras lagoas estudas, apresenta a menor profundidade, recebendo uma maior incidência de luz, favorecendo o aumento da temperatura.

Dos valores encontrados relacionados aos outros parâmetros analisados, os resultados relacionados à matéria orgânica e produtividade primária, tais como, amônia, DQO, turbidez e fósforo, foram os que mais influenciaram nos resultados. De um modo geral, houve uma padronização dos resultados encontrados, mostrando um relevante grau de semelhança entre as lagoas, entretanto a Lagoa do Jacaré se manteve com valores diferenciais nos parâmetros que garantiram a ela características fitofisionômicas distintas das outras 
lagoas do parque. Nas análises referentes à amônia, a Lagoa do Jacaré obteve o maior valor registrado, indicando que a lagoa está com uma elevada taxa de matéria orgânica, resultante normalmente do processo de eutrofização do corpo d'água ou do aporte de efluentes. Como não foi evidenciada nenhuma indicação de contaminação por efluentes domésticos, industriais, ou afluxo de fertilizantes, o alto valor de amônia encontrado na lagoa é resultante da alta taxa de decomposição das espécies encontradas, que aumentaram os nutrientes disponíveis na água, estimulando o processo de eutrofização.

A grande quantidade de matéria orgânica encontrada na lagoa é decorrente da proliferação e decomposição de macrófitas aquáticas, que no caso da lagoa em questão tem a presença marcante da espécie Eleocharis interstincta (junco), planta emergente com excelente propagação vegetativa que facilmente estabelece populações homogêneas tornando-se rapidamente infestante (Mestre, 2014; Gomes \& Aoki, 2015). O resultado da decomposição da matéria orgânica dessas plantas aumenta a liberação de amônia que sofrerá decomposição por microrganismos, provocando o consumo de oxigênio dissolvido das águas naturais ao ser oxidada biologicamente. Sendo assim, além da alta taxa de amônia encontrada é possível perceber que a Lagoa do Jacaré teve o maior índice de DQO, que é um parâmetro utilizado para identificar a presença de matéria orgânica na água. Logo, o alto valor da demanda química de oxigênio na lagoa, indica o elevado consumo de oxigênio necessário para estabilizar essa matéria orgânica disponível.

Outro parâmetro observado que justifica o processo de infestação da Lagoa do Jacaré é o fósforo, que tem sua presença na água relacionada à decomposição da matéria orgânica e ou atividade antrópica (Dias, 2014; Londe et al., 2015). O fósforo, por ser 
essencial na constituição das moléculas que atuam nos processos metabólicos das plantas aquáticas e sendo também elemento restringente de produtividade primária, sendo descrito por Fonseca \& Bicudo (2011) e Fermino et al., (2011) em estudos no Lago das Ninféias como fator limitante das comunidades botânicas, o excesso da disponibilidade do fósforo na água estimula o processo de eutrofização. Logo, um dos fatores que influenciou a infestação da lagoa por macrófitas aquáticas foi à alta taxa de decomposição das espécies encontradas, aumentando os nutrientes disponíveis na água, favorecendo o surgimento de novos indivíduos, retroalimentando o ciclo infestante.

Além da amônia e fósforo, outro parâmetro estudado, que tem relação direta com matéria orgânica disponível na água é a turbidez, ela é causada pela dispersão dos raios luminosos devido à presença de partículas em suspensão. As lagoas do Junco e do Jacaré que apresentam águas escuras cor de chá, obtiveram os maiores valores registrados; tais valores são resultados do alto índice de decomposição da matéria orgânica de macrófitas como o junco, que infestam essas lagoas. Em contra partida, as lagoas Alameda e Vitória, que, apesar de terem a cor da água entre tons de marrom e amarelo, resultantes da presença de materiais orgânicos dissolvidos, obtiveram os menores valores referentes à turbidez. Logo, mesmo tendo a presença de matéria orgânica disponível, fatores como densas populações homogêneas infestantes não existem nessas lagoas e não foram evidenciados processos que corroborem com o aumento da decomposição da matéria orgânica.

\section{Conclusões}

Por ser último manancial urbano do ecossistema de dunas, lagoas e restingas do Brasil, é imprescindível o conhecimento da biota do Parque das Dunas. Sendo assim, o presente estudo tem grande 
representatividade neste âmbito. O inventário florístico das macrófitas aquáticas do parque fornece um grande subsídio para estudos futuros, além de ter grande valia profissional, pois, a região onde está localizado o parque, bem como todo o Litoral Norte do estado da Bahia, sofre intensa especulação imobiliária, industrial e turística. Concomitantemente ao inventário florístico, a análise dos parâmetros físico-químicos gerou importantes dados para as pesquisas futuras em toda região, visto que, os estudos comumente se resumem em análises de pouquíssimos parâmetros relacionados geralmente a uma espécie de macrófita. Neste trabalho foi possível verificar a relação dos parâmetros, principalmente os relacionados à matéria orgânica, com as espécies de macrófitas aquáticas, resultando na identificação de um processo de infestação de Eleocharis interstincta na Lagoa do Jacaré.

Por fim, com os resultados encontrados será possível construir, de maneira mais eficiente, propostas de planejamento ambiental e manejo das macrófitas aquáticas do parque, principalmente nas lagoas do Jacaré, que está em um acentuado grau de infestação e Junco, que possui uma colonização considerável de Eleocharis interstincta. Além disso, sugerem-se, pesquisas sobre a composição bioquímica das lagoas a fim de verificar o índice de qualidade

\section{Referências}

ALVES, J. A. A. et al. Composição e distribuição de macrófitas aquáticas na lagoa da Restinga do Massiambu, Área de Proteção Ambiental Entorno Costeiro, SC. Rodriguésia 62(4): 785-801. 2011.

ARAÚJO, M. A. M. et al. Composição e Riqueza de Espécies de Poaceae Determinada pela Inundação Sazonal na Savana de Roraima, Norte da Amazônia Brasileira. In. Livro de Resumos do III Simpósio CENBAM e PPBio Amazônia Ocidental. Manaus - AM, 2015.

AZEVEDO, N.H.; et al. Ecologia na restinga: uma sequência didática argumentativa. 1oed. São Paulo: Edição dos autores, Janeiro de 2014. 140p.

BOVE, C. P. et al. Hidrófitas Fanerogâmicas de Ecossistemas Aquáticos Temporários da Planície Costeira do Estado do Rio de Janeiro, Brasil. Acta bot. bras. 17(1): 119-135. 2003.

CERVI, A.C. et al. Macrófitas aquáticas do Município de General Carneiro, Paraná, Brasil. Biota Neotrop. 2009, 9(3): 215-222.

CONAMA - CONSELHO NACIONAL DO MEIO AMBIENTE. RESOLUÇÃO No 357, DE 17 DE MARÇO DE 2005. Publicada no DOU no 053, de 18/03/2005, págs. 58-63.

CUNHA-SANTINO, M. B. da \& BIANCHINI JR., I. Colonização de macrófitas aquáticas em ambientes lênticos. Universidade Federal de São Carlos. Departamento Hidrobiologia. São Paulo, 2011. 
ESTEVES, F.A. Fundamentos da Limnologia. Org. 1a Ed. Rio de janeiro: Editora Interciência/ FINEP, 1998, 602p. 2011, 184p.

Fundamentos da Limnologia. Org. 3a Ed. Rio de janeiro: Editora Interciência,

FERMINO, S.F. et al. Seasonal influence of nitrogen and phosphorus enrichment on the floristic composition of the algal periphytic community in a shallow tropical, mesotrophic reservoir (São Paulo, Brazil). Oecologia Australis. 2011. 15: 476-493. 2011, 84p.

FERREIRA, F.A. et al. Estrutura da comunidade de macrófitas aquáticas em três lagoas do Parque Estadual do Rio Doce, Minas Gerais, Brasil. Hoehnea 37(1): 43-52, 1 tab., 6 fig., 2010.

INEMA - INSTITUTO DO MEIO AMBIENTE E RECURSOS HÍDRICOS -. APA Lagoas e Dunas do Abaeté. Disponível em: <http://www.inema.ba.gov.br/gestao-2/unidades-deconservacao/apa/apa-lagoas-e-dunas-do-abaete/> Acesso em: 04 de dezembro de 2015.

JUNK, W.J. et al. Definição e Classificação das Áreas Úmidas (AUs) Brasileiras: Base Científica para uma Nova Política de Proteção e Manejo Sustentável. Instituto Nacional de Ciências e Tecnologia em Áreas Úmidas. Centro de Pesquisa do Pantanal. Mato Grosso, 2014

LACET, J. B. Macrófitas Aquáticas do Balneário das Águas Minerais - Santa Rita, PB. Trabalho de Conclusão de Curso_TCC (Graduação em Bacharel em Ciências Biológicas). Universidade Estadual da Paraíba. João Pessoa - PB, 2014.

LOPES, A. et al. Herbáceas Aquáticas em Seis Igapós na Amazônia Central: Composição e Diversidade de Gêneros. Rev. Geogr. Acadêmica v.8, n.1; vii. 2014.

MAUHS. J. et al. Riqueza e biomassa de macrófitas aquáticas em uma área úmida na planície costeira do Rio Grande do Sul, Brasil. Pesquisa Botânica, São Leopoldo, Instituto Anchietano de Pesquisas. no 57, p.289-302, 2006.

MENEZES, C. M.; A vegetação de restinga no Litoral Norte da Bahia, influência da evolução quaternária da zona costeira: Estudo de caso fazenda riacho das flores, Mata de São João, Bahia. Salvador: UFBA, 2007. 96p. Dissertação (Mestrado em Geologia). Programa de Pós-Graduação em Geologia, Instituto de Geociências, Universidade Federal da Bahia, Salvador, 2007.

et al. Florística e Fitossociologia do componente arbóreo do município de Conde, Bahia, Brasil. REVISTA BIOCIÊNCIAS, UNITAU. Volume 15, número 1, 2009.

MESTRE, A. B. Contribuição para o Estudo de Propagação e Produção de Plantas Aquáticas. Dissertação (Mestrado em Arquitectura Paisagista). Universidade de Lisboa. Lisboa, 2014.

PAZ, J. \& BOVE, C. P. Hidrófitas Vasculares da Lagoa de Carapebus, Parque Nacional da Restinga de Jurubatiba, Rio de Janeiro, Brasil. Revista Brasileira de Biociências, Porto Alegre, v. 5, supl. 2, p. 495-497, jul. 2007.

POLLOCK, M.M. et al. Plant species richness in riparian Wetlands - A test of biodiversity theory. Ecology 79(1): 94-105. 1998.

POMPÊO, M. L. M. \& MOSCHINI-CARLOS, V. Macrófitas aquáticas e perifíton: Aspectos Ecológicos e Metodológicos. São Paulo: Rima, 2003. 10p. 
POTT, V.J. \& POTT, A. Plantas aquáticas do Pantanal. Brasília: Embrapa, 2000. 404 p. . Macrófitas Aquáticas do Pantanal e de outras áreas úmidas em Mato Grosso do Sul. Heringeriana Brasília. V.6. no1, p. 72-75, Agosto de 2012.

PRATA, A. P. Anatomia do escapo e rizoma de espécies brasileiras de Bulbostylis Kunth (Cyperaceae). Revista Brasil. Bot., V.30, n.2, p.245-256, abr.-jun. 2007.

RODRIGUES, M. E. F. Levantamento florístico e distribuição de macrófitas aquáticas na Represa Guarapiranga, São Paulo, Brasil. Dissertação (Mestrado em Botânica). Instituto de Biociências da Universidade de São Paulo. São Paulo, 2011.

SANTOS, E. et al. O Caminho das Águas em Salvador: Bacias Hidrográficas, Bairros e Fontes. Centro Interdisciplinar de Desenvolvimento e Gestão Social -CIAGS/UFBA; Secretaria do Meio Ambiente do Estado da Bahia - SEMA. Salvador, 2010.

TINÔCO, M. S. et al. Habitat change and amphibian conservation in the Atlantic Forest of Bahia, Brazil. Froglog Newsletter of the IUCN/SSC Amphibian Specialist Group, 2008.

TUNDISI, J. G. Novas perspectivas para gestão de recursos hídricos. Revista USP, São Paulo, n.70, p. 24-35, junho/agosto 2006.

TUNDISI, J.G.; MATSUMURA-TUNDISI, T. Limnologia, São Paulo: Oficina de Textos, 2008, 632 p. 